\title{
Alcohol Use and Periodic Limb Movements of Sleep
}

\author{
Michael S. Aldrich and James E. Shipley
}

\begin{abstract}
Alcohol causes significant sleep disturbance but the causes are not well understood. We investigated the relationship between alcohol use and periodic limb movements in a large population of patients at a sleep disorders center. The likelihood of having a clinically significant number of periodic leg movements (more than 20 per hour of sleep) was increased 3-fold in women who consumed two or more alcoholic drinks per day compared with those who did not (25\% versus $8 \%$ ). A similar relation was found among men $(22 \%$ versus $13 \%$ ). In addition, women who consumed two or more drinks per day were more likely to report symptoms of restless legs and to be diagnosed with restless legs syndrome. These findings suggest that periodic leg movements contribute to sleep disturbance in a significant proportion of alcohol users. Alcohol use may increase the frequency of periodic leg moverments in susceptible individuals. On the other hand, subjects with symptoms related to periodic leg movements may be using alcohol to relieve symptoms, or the movements may be secondary to alcohol-induced sleep disturbance.

Key Words: Alcohol, Periodic Leg Movements, Nocturnal Myoclonus, Sleep, Sleep Disorders.
\end{abstract}

$\mathbf{A}^{\mathrm{L}}$ LCOHOL USE LEADS TO disturbed sleep, but the causes of sleep disruption are not well understood. Although alcohol intake at bedtime shortens the time to the onset of sleep, the amount of wakefulness in the second half of the night is increased ${ }^{1,2}$; even a single low dose of alcohol increases sleep fragmentation and the number of awakenings. ${ }^{3}$ Alcohol also alters the architecture of sleep: the amount of rapid eye movement (REM) sleep is reduced and the amount of slow wave sleep is increased. ${ }^{4}$ Tolerance to many of these effects develops within a few nights but when ethanol intake at bedtime is discontinued there is a rebound increase in REM sleep, a decrease in slow wave sleep, and an increase in nocturnal wakefulness. ${ }^{1,4}$ Chronic alcoholism is associated with severe disorganization of sleep architecture with frequent awakenings, disrupted REM sleep, and reduced amounts of slow wave sleep. ${ }^{5}$ Nocturnal alcohol use also leads to an increase in sleep apnea in susceptible individuals. ${ }^{6-9}$

Periodic leg movements (PLMs), a well-recognized cause of disturbed sleep,$^{10}$ are a potential contributor to the sleep disruption associated with alcohol use. The

From the Departments of Ncurology (M.S.A.) and Psychiatry (J.E.S.), University of Michigan Alcohol Research Center, Ann Arbor, Michigan.

Received for publication May 18, 1992: accepted August 25, 1992

This work was supported in part by the National Institute on Alcohol Abuse and Alcoholism Grant AA07378.

Presented in part at the 1989 annual meeting of the Research Society on Alcoholism.

Reprint requests: Michael S. Aldrich, M.D., Department of Neurology, Taubman Center 1920, Box 0316. University of Michigan Medical C'enter, 1500 East Medical Center Drive, Ann Arbor, MI 48109-0316.

Copvright (C) 1993 by The Research Society on Alcoholism. movements, ranging from slight dorsiflexion of the great toe to vigorous kicks with dorsiflexion at the ankle, extension at the knee, and flexion at the hip may produce no alteration of EEG sleep patterns, a brief arousal, or a full awakening. They usually occur as a series of movements every 20 to $30 \mathrm{sec}$, lasting for a few minutes or for an hour or more. Vigorous movements often disrupt the sleep of the bed partner as well.

Although the cause of PLMs is not known, they are thought to be the result of disinhibition of a central pacemaker regulating reticular excitability. ${ }^{10,11}$ Certain predisposing factors are recognized including renal failure. iron deficiency, anemia, and pregnancy. PLMs occur in up to $90 \%$ of patients with the restless legs syndrome, a disorder associated with uncomfortable leg sensations that are difficult to describe, worse at night, and that are associated with an almost irresistible urge to move the legs. In addition, some diseases of the CNS, such as Parkinson's disease, are associated with PLMs, presumably as a result of toxic or degenerative effects on the brain. ${ }^{12.13}$

Although PLMs are common, there have been few investigations of their relationship to alcohol use. In four subjects with PLMs, Scrima et al. ${ }^{14}$ found a reduction in the arousals associated with PLMs but little effect on the overall frequency of the leg movements after an evening dose of alcohol. Many studies of the effects of alcohol on sleep have not included leg movement monitors. We therefore reviewed clinical and polysomnographic data relating to PLMs and alcohol use in a large consecutive series of patients seen at a sleep disorders center.

\section{METHODS}

The study population consisted of consecutive adults age 19 years or older who underwent clinical evaluation at the University of Michigan Sleep Disorders Center between 1987 and 1991. For this study, we included all patients who had completed a detailed questionnaire assessing sleep habits and related information and who were monitored for at least one night of baseline polysomnography. The questionnaire is a modified 181-item version of the Sleep Questionnaire and Assessment of Wakefulness (SQAW). ${ }^{\text {is }}$

Polysomnographic monitoring was performed by experienced polysomnographic technologists using standard techniques for assessment of clinical sleep disorders. ${ }^{16-19}$ EEG (C3, C4, O1, O2 by International 1020 system), chin electromyogram (EMG), and electrooculogram were monitored continuously using standard polysomnographic techniques. ${ }^{16}$ Mercury strain gauges on chest and abdomen were used to monitor respiratory effort, and thermistors at the nose and mouth were used to monitor airflow. Leg movements were monitored bilaterally with surface EMG electrodes over the anterior tibialis muscles. Oxygen saturation was monitored by pulse oximetry (Biox 3700. Ohmeda Corporation). 
Nocturnal recordings were made at $10 \mathrm{~mm} / \mathrm{sec}$ paper speed using 17 or 21 channel polygraphs (Nihon-Kohden Corporation of America, Irvine, CA: Grass Instruments; Quincy, MA). The recordings were scored for sleep stages and respiratory measurements using standard techniques. ${ }^{16,18,19} \mathrm{~A}$ respiratory disturbance index was calculated as the number of apneas plus hypopneas per hour of sleep. Anterior tibialis EMG activity was scored as a PLM if the activity occurred during sleep, lasted 0.5 to $5 \mathrm{sec}$, and occurred in a series of at least four movements separated by intervals of more than $5 \mathrm{sec}$ and less than $90 \mathrm{sec}^{19,20}$ A PLM index (PLMI) was calculated as the number of minutes with PLMs divided by the number of hours of sleep.

Based on clinical, questionnaire, and polysomnographic assessment, all subjects were diagnosed according to the International Classification of Sleep Disorders. ${ }^{20}$ As part of the questionnaire, subjects were asked to describe their average daily weekday and weekend consumption of beer, wine, and mixed drinks. From this data, the average number of drinks per day was computed assuming one drink was equivalent to one beer, one glass of wine, or one mixed drink. Subjects were then divided into two groups: those with average alcohol intake of less than two drinks per day (Group I: abstainers and light to moderate users) and those with average intake of 2 or more drinks per day (Group II: heavy users). All subjects were free of alcohol during polysomnography.

We compared the two groups with regard to polysomnographic findings, with particular reference to PLMs, and to questionnaire items potentially relating to PLMs. Statistical comparisons were made using analysis of variance, Spearman rank correlations, and $\chi^{2}$ contingency tables (Statgraphics; STSC, Inc., Rockville, MD).

\section{RESULTS}

The study group consisted of 643 men and 341 women with a mean age of 48 years (range 19 to 81 ). Sleep disorder diagnoses for the subject population are shown in Table 1 ; the most common primary diagnoses were sleep apnea (present in $40 \%$ of women and $71 \%$ of men), narcolepsy ( $14 \%$ of women and $7 \%$ of men), and other hypersomnias

\begin{tabular}{|c|c|c|c|c|c|c|}
\hline \multirow[b]{2}{*}{ Group } & \multicolumn{3}{|c|}{ Women } & \multicolumn{3}{|c|}{ Men } \\
\hline & 1 & II & Total & 1 & II & Total \\
\hline \multicolumn{7}{|l|}{ Intrinsic sleep disorders } \\
\hline Psychophysiologic/idiopathic insomnia & $2 \%$ & & $2 \%$ & $1 \%$ & $1 \%$ & $1 \%$ \\
\hline Narcolepsy & $15 \%$ & $8 \%$ & $14 \%$ & $6 \%$ & $7 \%$ & $7 \%$ \\
\hline Sleep apnea & $40 \%$ & $50 \%$ & $44 \%$ & $70 \%$ & $74 \%$ & $71 \%$ \\
\hline PLMs & $2 \%$ & $4 \%$ & $2 \%$ & $4 \%$ & $6 \%$ & $4 \%$ \\
\hline Restless legs syndrome & $2 \%$ & $13 \%$ & $3 \%$ & $1 \%$ & & $1 \%$ \\
\hline Hypersomnia-uncertain cause & $8 \%$ & $8 \%$ & $8 \%$ & $2 \%$ & $2 \%$ & $2 \%$ \\
\hline Other & $2 \%$ & & $1 \%$ & $0.4 \%$ & & $0.3 \%$ \\
\hline \multicolumn{7}{|l|}{ Extrinsic and circadian sleep disorders } \\
\hline Insufficient sleep & $6 \%$ & & $5 \%$ & $2 \%$ & $1 \%$ & $2 \%$ \\
\hline Delayed sleep phase syndrome & $0.6 \%$ & & $0.6 \%$ & $0.4 \%$ & & $0.3 \%$ \\
\hline Other & $2 \%$ & & $1 \%$ & $1 \%$ & $1 \%$ & $1 \%$ \\
\hline Parasomnias & $5 \%$ & $8 \%$ & $6 \%$ & $3 \%$ & & $2 \%$ \\
\hline $\begin{array}{l}\text { Sleep disorders associated with psychi- } \\
\text { atric, neurologic, or medical dis- } \\
\text { eases }\end{array}$ & $8 \%$ & $8 \%$ & $8 \%$ & $5 \%$ & $7 \%$ & $5 \%$ \\
\hline \multicolumn{7}{|l|}{ Other } \\
\hline Subjective sleepiness only & $3 \%$ & & $3 \%$ & $1 \%$ & $1 \%$ & $1 \%$ \\
\hline No sleep pathology identified & $6 \%$ & & $5 \%$ & $2 \%$ & & $1 \%$ \\
\hline \multicolumn{7}{|l|}{ Total for each diagnostic category } \\
\hline Intrinsic & $71 \%$ & $84 \%$ & $72 \%$ & $86 \%$ & $90 \%$ & $86 \%$ \\
\hline Extrinsic & $8 \%$ & & $7 \%$ & $4 \%$ & $2 \%$ & $4 \%$ \\
\hline Parasomnias & $5 \%$ & $8 \%$ & $6 \%$ & $3 \%$ & & $2 \%$ \\
\hline Other disorders & $8 \%$ & $8 \%$ & $8 \%$ & $5 \%$ & $7 \%$ & $5 \%$ \\
\hline Other & $9 \%$ & & $8 \%$ & $2 \%$ & $1 \%$ & $2 \%$ \\
\hline No. of subjects & 317 & 24 & 341 & 555 & 88 & 643 \\
\hline
\end{tabular}

Group I: low alcohol use; Group II: high alcohol use.
( $8 \%$ of women and $2 \%$ of men). Five percent of women and men had a primary diagnosis of PLM disorder or restless legs syndrome.

Fourteen percent of the men $(n=88)$ and $7 \%$ of the women $(n=24)$ consumed an average of two or more alcoholic drinks per day. For Group I, those who described their average daily alcohol consumption as 0 to 1.99 drinks per day, mean alcohol use in drinks per day was 0.2 for men and 0.1 for women; in those who described average daily alcohol consumption of two or more drinks per day (Group II), mean alcohol use in drinks per day was 4.0 for men (range 2.0 to 27.0) and 3.6 (range 2.0 to 10.9) for women. Sleep disorder diagnoses and mean age were similar between the two groups (Table 1).

For men and women, sleep architecture was similar in Groups I and II (Table 2). As sleep apnea often produces marked sleep disruption with associated periodic and quasiperiodic arousals and movements that may be difficult to distinguish from primary periodic limb movements, we also divided patients into those with a primary diagnosis of sleep apnea and those without.

In men and women, PLMs were more frequent in Group II (Table 2, Fig. 1). The proportion of men with PLMI greater than 20 was $13 \%$ in Group I and $22 \%$ in Group II $(p=0.031)$. Among women, $25 \%$ in Group II had a PLMI greater than 20 compared with $8 \%$ of lightmoderate drinkers $(p=0.004)$. The differences were more striking in patients without sleep apnea: $39 \%$ of men and $42 \%$ of women in Group II had a PLMI > 20 compared with $20 \%$ of men and $9 \%$ of women in Group I ( $p=$ 0.039 for men; $p=0.0004$ for women). Seventeen percent of women in Group II had a primary diagnosis of PLM disorder or restless legs syndrome compared with $4 \%$ of women in Group I $\left(\chi^{2}=6.69 ; p=0.010\right)$.

For all subjects, there was a weak correlation between self-described alcohol use and PLMI (Spearman rank correlation coefficient $=0.049 ; p=0.11$ ), but there was little difference in the PLMI between those who consumed less than one drink per day and those who consumed one to two drinks per day. Only $2.6 \%(n=26)$ of the total subject population consumed more than four alcoholic drinks per day and the mean PLMI in these subjects was less than in the $8.7 \%(n=86)$ who consumed two to four drinks per day (Fig. 1).

Based on questionnaire assessment, women in Group II were more likely to experience restless legs symptoms ( $42 \%$ versus $23 \% ; F=4.50, p=0.035$ ), and women in Group II without sleep apnea were more likely to describe kicking leg movements at night (Table 3). There were no significant differences in reports of symptoms of nocturnal leg cramps or nocturnal paresthesias for men or for women.

\section{DISCUSSION}

We found that a clinically significant frequency of PLMs (more than 20 per hour of sleep) is more likely to occur 
Table 2. Polysomnographic Findings

\begin{tabular}{|c|c|c|c|c|c|c|}
\hline \multirow[b]{2}{*}{ Diagnosis group } & \multicolumn{2}{|c|}{ All subjects } & \multicolumn{2}{|c|}{ Sleep apnea-present } & \multicolumn{2}{|c|}{ Sleep apnea-absent } \\
\hline & $\begin{array}{c}\text { I } \\
\text { Low alcohol } \\
\text { use }\end{array}$ & $\begin{array}{c}\text { II } \\
\text { High alcohol } \\
\text { use }\end{array}$ & $\begin{array}{c} \\
\text { Low alcohol } \\
\text { use }\end{array}$ & $\begin{array}{c}\text { " } \\
\text { High" alco- } \\
\text { hol use }\end{array}$ & $\begin{array}{c} \\
\text { Low alcohol } \\
\text { use }\end{array}$ & $\begin{array}{c}\text { II } \\
\text { High alcohol } \\
\text { use }\end{array}$ \\
\hline
\end{tabular}

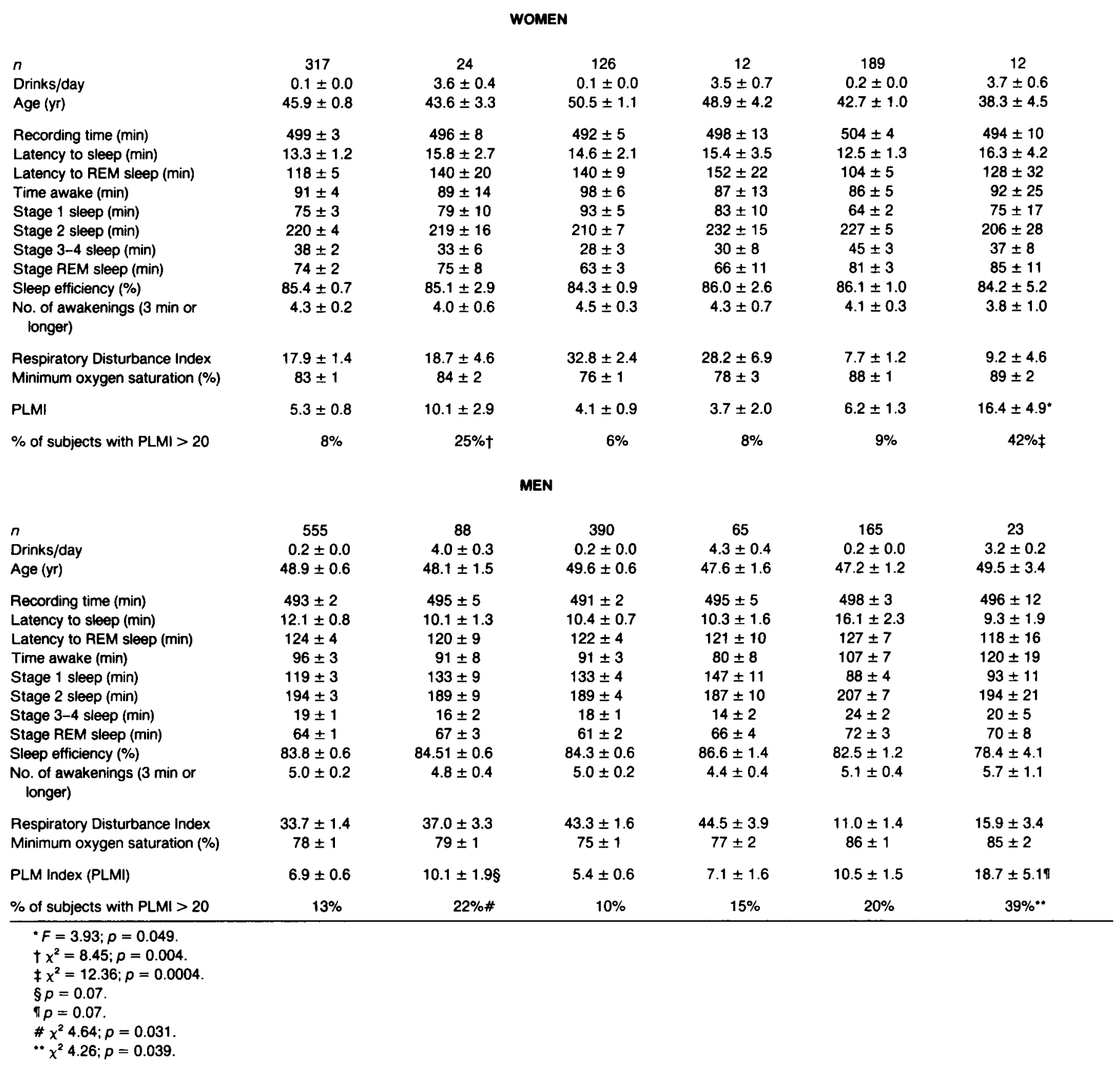

in subjects who drink two or more alcoholic beverages per day than in those who do not. In addition, among women undergoing sleep center evaluation, those who drink two or more drinks per day are more likely than those who drink less to have a primary diagnosis of PLM disorder or restless legs. The findings are based on the subjects' assessments of their own alcohol use; actual alcohol intake may have varied considerably from these self-reports.
There are several possible explanations for this association between drinking behavior and PLMs. First, toxic effects of alcohol on the CNS might be the cause of the association. ${ }^{21}$ Chronic alcohol use produces a variety of perturbations of brain function, some of which appear to be mediated by effects on the inhibitory neurotransmitter $\gamma$-aminobutyric acid. ${ }^{21}$ As reduced inhibition of an intrinsic subcortical pacemaker may be the neurophysiological 


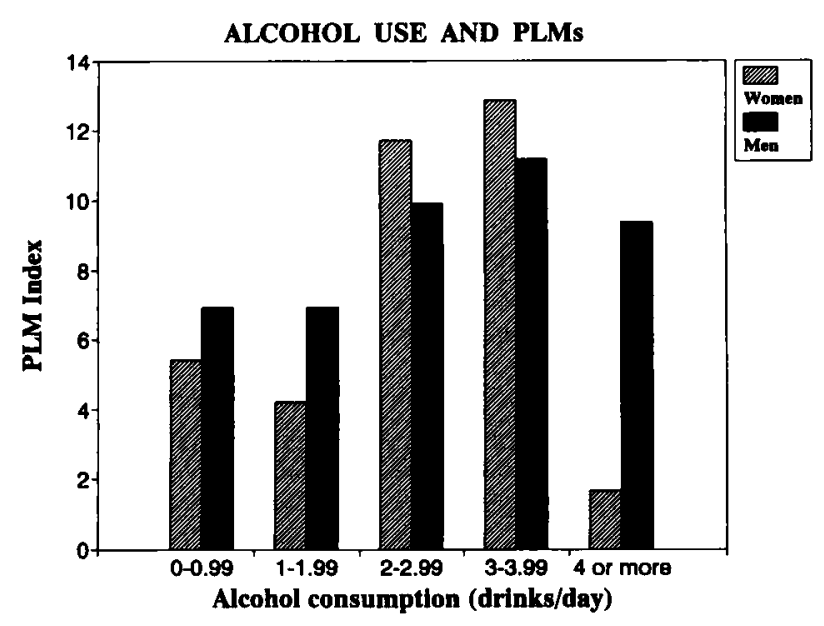

Fig. 1. Mean PLMI versus mean alcohol consumption. There is little difference in PLMI among groups of subjects who consume less than two drinks per day. Those who consume four or more drinks per day have a lower PLMI than those who consume two to four drinks per day, suggesting a threshold effect for alcohol use on PLMs.

basis for PLMs, ${ }^{11}$ such effects could account for this relationship.

Second, it may be that alcohol use triggers or releases PLMs in susceptible individuals. PLMs can be caused or exacerbated by a number of agents and conditions, including tricyclic antidepressants, caffeine, withdrawal from benzodiazepines, and exposure to cold. Thus, relatively small perturbations of the nervous system may be sufficient to produce these movements in susceptible persons. The apparent threshold effect of alcohol on PLMs that we observed is consistent with this hypothesis. PLMs are often present in asymptomatic relatives of patients with restless legs syndrome, suggesting that some persons may have an increased tendency to such movements.

Third, subjects with symptoms related to PLMs, such as restless legs, may use alcohol to relieve symptoms. We found that women, but not men, who consumed two or more drinks per day were more likely to report frequent symptoms of restless legs. Alcohol has sleep-inducing effects, and such patients may be using alcohol to promote sleep. However, it may be that alcohol has deleterious effects on the condition, PLMs, for which it is self-prescribed.

Fourth, PLMs may be a consequence of alcohol-induced sleep disturbance rather than a primary cause of sleep disturbance. PLMs occur in a wide variety of conditions causing sleep disturbance, including sleep apnea and narcolepsy. Sleep disruption with frequent arousals and increased amounts of light non-REM sleep may increase the likelihood that PLMs will be expressed.

It is unlikely that peripheral neuropathy related to alcohol use is responsible for the association we observed. The association between PLMs and alcohol use was apparent in moderate alcohol users, and in sleep studies of rigorously diagnosed alcoholics, we have not found an increase in PLMs (Aldrich MS and Shipley JE, unpub-
Table 3. Symptoms Potentially Related to PLMs

\begin{tabular}{|c|c|c|c|}
\hline & Question no. & $\begin{array}{c}\text { Group I } \\
\text { Low alcohol use } \\
\text { Mean } \pm \text { SEM }\end{array}$ & $\begin{array}{c}\text { Group II } \\
\text { High alcohol use } \\
\text { Mean } \pm \text { SEM }\end{array}$ \\
\hline Men & 1 - "kick" & $22.1 \% \pm 2.1 \%$ & $17.7 \% \pm 4.7 \%$ \\
\hline \multirow{3}{*}{ Sleep apnea-present } & 2 - "restless" & $13.6 \% \pm 1.7 \%$ & $9.2 \% \pm 3.6 \%$ \\
\hline & 3 - "cramps" & $8.7 \% \pm 1.4 \%$ & $7.8 \% \pm 3.3 \%$ \\
\hline & 4 - "paresthesias" & $9.7 \% \pm 1.5 \%$ & $11.1 \% \pm 3.9 \%$ \\
\hline Men & 1 - "kickn" & $22.3 \% \pm 3.2 \%$ & $31.8 \% \pm 9.7 \%$ \\
\hline \multirow[t]{3}{*}{ Sleep apnea-absent } & 2 - "restless" & $17.4 \% \pm 3.0 \%$ & $8.7 \% \pm 5.9 \%$ \\
\hline & 3 - "cramps" & $7.3 \% \pm 2.0 \%$ & $13.0 \% \pm 7.0 \%$ \\
\hline & 4 - "paresthesias" & $8.5 \% \pm 2.2 \%$ & $4.5 \% \pm 4.3 \%$ \\
\hline Men & 1 - "kick" & $22.1 \% \pm 1.8 \%$ & $21.4 \% \pm 4.4 \%$ \\
\hline \multirow{3}{*}{ Total } & 2 - "restless" & $14.8 \% \pm 1.5 \%$ & $9.1 \% \pm 3.1 \%$ \\
\hline & 3 - "cramps" & $8.3 \% \pm 1.2 \%$ & $9.2 \% \pm 3.1 \%$ \\
\hline & 4 - "paresthesias" & $9.4 \% \pm 1.2 \%$ & $9.4 \% \pm 3.1 \%$ \\
\hline Women & 1- "kick" & $22.0 \% \pm 3.7 \%$ & $0.0 \% \pm 0.0 \%$ \\
\hline \multirow[t]{3}{*}{ Sleep apnea-present } & 2 - "restless" & $20.8 \% \pm 3.6 \%$ & $25.0 \% \pm 2.5 \%$ \\
\hline & 3 - "cramps" & $13.8 \% \pm 3.1 \%$ & $25.0 \% \pm 12.5 \%$ \\
\hline & 4 - "paresthesias" & $21.3 \% \pm 3.6 \%$ & $27.3 \% \pm 12.9 \%$ \\
\hline Women & 1 - "kick" & $22.3 \% \pm 3.0 \%$ & $50.0 \% \pm 14.4 \%$ \\
\hline \multirow[t]{3}{*}{ Sleep apnea-absent } & 2 - "restless" & $23.7 \% \pm 3.1 \%$ & $58.3 \% \pm 14.2 \% \dagger$ \\
\hline & 3 - "cramps" & $12.0 \% \pm 2.4 \%$ & $0.0 \% \pm 0.0 \%$ \\
\hline & 4 - "paresthesias" & $19.0 \% \pm 2.9 \%$ & $25.0 \% \pm 12.5 \%$ \\
\hline Women & 1 - "kick" & $22.2 \% \pm 2.3 \%$ & $25.0 \% \pm 8.8 \%$ \\
\hline \multirow[t]{3}{*}{ All } & 2 - "restless" & $22.5 \% \pm 2.4 \%$ & $41.7 \% \pm 10.1 \% \ddagger$ \\
\hline & 3 - "cramps" & $12.7 \% \pm 1.9 \%$ & $13.0 \% \pm 6.9 \%$ \\
\hline & 4 - "paresthesias" & $19.9 \% \pm 2.3 \%$ & $26.1 \% \pm 9.0 \%$ \\
\hline
\end{tabular}

Percentages shown are for those answering "often" or "almost always" to the following questions:

Question 1: How often do your legs twitch or kick during the night while you are asleep?

Question 2: When falling asleep or during the night, how often is your sleep disturbed because of restless legs (crawling or aching feelings and inability to keep your legs still)?

Question 3: When falling asleep or during the night, how often is your sleep disturbed because of leg cramps (charlie horses)?

Question 4: When falling asleep during the night, how often is your sleep disturbed because of paresthesias ("pins and needles") in your arms or legs?

Response categories for each question were "never," "seldom," "occasionally," "often," and "almost always."

$\chi^{2}=3.93 ; \rho=0.047$.

$\dagger x^{2}=7.01 ; \rho=0.008$

$\ddagger \chi^{2}=4.47 ; p=0.035$

lished data). These findings suggest two or more drinks per day may "release" PLMs in susceptible individuals.

In summary, our findings suggest that PLMs may be a contributor to disordered sleep in a substantial proportion of persons who consume two or more alcoholic drinks per day and have sleep complaints. Research studies of sleep disturbance in alcohol users should include leg movement monitoring.

\section{REFERENCES}

1. Roth T, Roehrs T, Zorick F, Conway W: Pharmacological effects of sedative-hypnotics, narcotic analgesics, and alcohol during sleep. Med Clin North Am 69:1281-1288, 1985

2. Prinz PN, Roehrs TA, Vitaliano PP, et al.: Effect of alcohol on sleep and nighttime plasma growth hormone and cortisol concentrations. J Clin Endocrinol Metab 51:759-764, 1980

3. Rouhani S, Tran G, Leplaideur F, Durlach J, Poenaru S: EEG effects of a single low dose of ethanol on afternoon sleep in the nonalcohol-dependent adult. Alcohol 6:87-90, 1989 
4. Yules RB, Freedman DX, Chandler KA: The effect of ethyl alcohol on man's electroencephalographic sleep cycle. Electroencephalogr Clin Neurophysiol 20:109-111, 1966

5. Lester BK, Rundell OH, Cowden LC, et al.: Chronic alcoholism, alcohol and sleep. Adv Med Exp Biol 35:261-279, 1973

6. Guilleminault C: Sleep apnea syndromes: Impact of sleep and sleep states. Sleep 3:227-234, 1980

7. Issa FG, Sullivan CE: Alcohol, snoring and sleep apnoea. J Neurol Neurosurg Psychiatry 45:353-359, 1982

8. Scrima L, Broudy M, Nay KN, Cohn MA: Increased severity of obstructive sleep apnea after bedtime alcohol ingestion: diagnostic potential and proposed mechanism of action. Sleep 5:318-328, 1982

9. Taasen VC, Block AJ, Boysen PG, Wynne JW, White C, Lindsey $S$ : Alcohol increases sleep apnea and oxygen desaturation in asymptomatic men. Am J Med 71:240-245, 1981

10. Montplaisir J, Godbout R: Restless legs syndrome and periodic movements of sleep, in Kryger MH, Roth T, Dement WC (eds): Principles and Practice of Sleep Medicine. Philadelphia, WB Saunders, 1989, pp 402-409

11. Coleman RM. Pollak CP. Weitzman ED: Periodic movements in sleep (nocturnal myoclonus): Relation to sleep disorders. Ann Neurol 8:416-421, 1980

12. Aldrich MS: Parkinsonism, in Kryger MH, Roth T, Dement WC (eds): Principles and Practice of Sleep Medicine. Philadelphia, WB Saunders, 1989, pp 351-357

13. Aldrich MS: Sleep and degenerative neurological disorders in- volving the motor system, in Thorpy $M J$ (ed): Handbook of Sleep Disorders. New York, Marcel Dekker, 1990, pp 673-692

14. Scrima L, Stedman D, Thomas E, Johnson F, Hiller FC: Arousals after alcohol ingestion in asymptomatic nocturnal myoclonus subjects. Sleep Res 15:168, 1986

15. Miles L: Appendix I, in Guilleminault $C$ (ed): Sleeping and Waking Disorders: Indications and Techniques. Menlo Park: AddisonWesley, 1982, pp 383-413

16. Rechtschaffen A, Kales A: A manual of standardized terminology, techniques, and scoring system for sleep stages of human subjects. Los Angeles, Brain Information Service/Brain Research Institute, 1968

17. Carskadon MA: Basics for polygraphic monitoring of sleep, in Guilleminault C (ed): Sleeping and Waking Disorders: Indications and Techniques. Menlo Park, Addison-Wesley, 1982, pp 1-16

18. Bornstein SK: Respiratory monitoring during sleep: polysomnography, in Guilleminault C (ed): Sleeping and Waking Disorders: Indications and Techniques. Menlo Park, Addison-Wesley, 1982, pp 183-212

19. Coleman RM. Periodic movements in sleep (nocturnal myoclonus) and restless legs syndrome, in Guilleminault $C$ (ed): Sleeping and Waking Disorders: Indications and Techniques. Menlo Park, Addison-Wesley, 1982, pp 265-295

20. International classification of sleep disorders: diagnostic and coding manual. Diagnostic Classification Steering Committee; Thorpy MJ (Chairman). Rochester, MN, American Sleep Disorders Association, 1990

21. Charness ME, Simon RP, Greenberg DA: Ethanol and the nervous system. N Engl J Med 321:442-453, 1989 